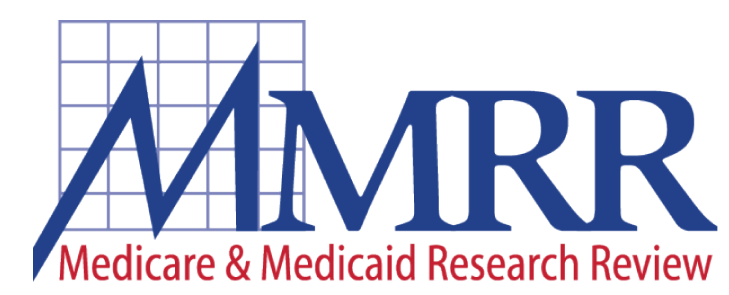

2013: Volume 3, Number 4

A publication of the Centers for Medicare \& Medicaid Services, Office of Information Products \& Data Analytics

\title{
Modeling Per Capita State Health Expenditure Variation: State-Level Characteristics Matter
}

\author{
Gigi Cuckler and Andrea Sisko
}

Centers for Medicare \& Medicaid Services-Office of the Actuary

Objective: In this paper, we describe the methods underlying the econometric model developed by the Office of the Actuary in the Centers for Medicare \& Medicaid Services, to explain differences in per capita total personal health care spending by state, as described in Cuckler, et al. (2011). Additionally, we discuss many alternative model specifications to provide additional insights for valid interpretation of the model.

Data Source: We study per capita personal health care spending as measured by the State Health Expenditures, by State of Residence for 1991-2009, produced by the Centers for Medicare \& Medicaid Services' Office of the Actuary. State-level demographic, health status, economic, and health economy characteristics were gathered from a variety of U.S. government sources, such as the Census Bureau, Bureau of Economic Analysis, the Centers for Disease
Control, the American Hospital Association, and HealthLeaders-InterStudy.

Principal Findings: State-specific factors, such as income, health care capacity, and the share of elderly residents, are important factors in explaining the level of per capita personal health care spending variation among states over time. However, the slow-moving nature of health spending per capita and close relationships among state-level factors create inefficiencies in modeling this variation, likely resulting in incorrectly estimated standard errors. In addition, we find that both pooled and fixed effects models primarily capture cross-sectional variation rather than period-specific variation.

Keywords: Health Care Costs, Health Spending Variation, Geographic Variation, Health Spending by State

ISSN: 2159-0354

doi: http://dx.doi.org/10.5600/mmrr.003.04.a03 


\section{Medicare \& Medicaid Research Review} 2013: Volume 3, Number 4

\section{Mission Statement}

Medicare \& Medicaid Research Review is a peerreviewed, online journal reporting data and research that informs current and future directions of the Medicare, Medicaid, and Children's Health Insurance programs. The journal seeks to examine and evaluate health care coverage, quality and access to care for beneficiaries, and payment for health services.

\section{http://www.cms.gov/MMRR/}

\section{U.S. Department of Health \& Human Services Kathleen Sebelius Secretary}

\section{Centers for Medicare \& Medicaid Services \\ Marilyn Tavenner Administrator}

Editor-in-Chief

David M. Bott, Ph.D.

The complete list of Editorial Staff and Editorial Board members may be found on the MMRR Web site (click link): $\underline{\text { MMRR Editorial Staff Page }}$

Contact: $\underline{\text { mmrr-editors@cms.hhs.gov }}$

Published by the Centers for Medicare \& Medicaid Services.

All material in the Medicare \& Medicaid Research Review is in the public domain and may be duplicated without permission. Citation to source is requested.

\section{Introduction}

Research exploring geographic variation in health spending has garnered increasing attention in health policy, including during the debate over, and passage of, health reform legislation. In December 2011, the Office of the Actuary (OACT) in the Centers for Medicare \& Medicaid Services (CMS) contributed to this research by releasing updated estimates of state health expenditure data for 19912009 and, for the first time in OACT's history, an econometric model to explain variation in total per capita personal health care spending across states over that period (Cuckler, et al., 2011). The purpose of the model was to further substantiate the findings of OACT's descriptive analysis of the macroeconomic and population-level factors that contribute to substantial variation observed in per capita personal health care spending ${ }^{1}$ levels by state (Exhibit 1). In total, this work provides valuable information for policymakers on historical statelevel health care spending trends, as well as context for futureanalysis of coverage expansions scheduled for 2014 under the Affordable Care Act.

In this paper, the methodology underlying OACT's econometric analysis of state health spending variation referenced in Cuckler et al. (2011) is described in greater detail. Thus, this paper contains a discussion of the relevant literature, methodological challenges, the data sources for the model, the econometric techniques and statistical tests used in the development of the published model, a sensitivity analysis, the results and implications of this analysis, limitations of the model, and areas for future research.

\footnotetext{
Personal health care spending includes the total amount spent to treat individuals with specific medical conditions, but excludes expenditures resulting from government administration, net costs of health insurance, government public health activity, non-commercial research, and investment in structures and equipment (CMS, 2012).
} 
Exhibit 1. State Personal Health Care Spending Per Capita as a Percent of U.S. Personal Health Care Spending Per Capita, 1 by State of Residence, for 1991-2009

(Minimum, Median and Maximum)

(National Average $=100$ )

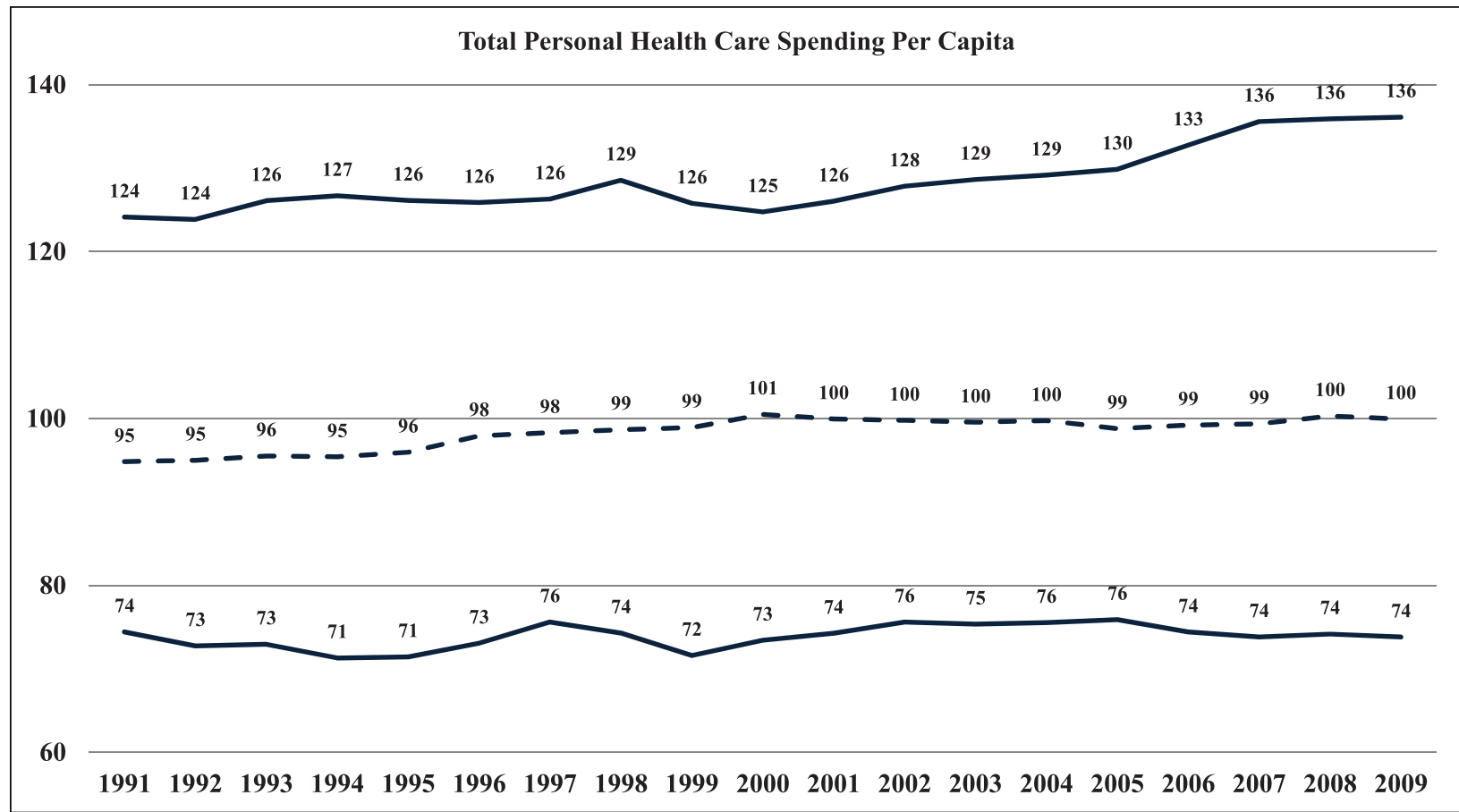

NOTE: 'State per capita Personal Health Care spending divided by U.S. per capita Personal Health Care spending. SOURCE: Centers for Medicare \& Medicaid Services, Office of the Actuary, National Health Statistics Group.

The OACT econometric analysis of state health spending variation joins a relatively small niche in the broader health spending variations literature, in which the state is the unit of analysis (i.e., Rettenmaier \& Saving, 2010; Di Matteo, 2005; L. Sheiner, personal communication, November 7, 2011; Rettenmaier \& Wang, 2012), and in which total personal health care spending per capita is the variable of interest (Rettenmaier \& Saving, 2010; Di Matteo, 2005). Our literature review identified key factors associated with differences in health spending across regions and states, including average income, general and/or medical prices, provider supply, population demographics, health status indicators, insurance coverage type and status, and a measure of time (specified using a linear trend or period fixed effects). The study of per capita health spending at the state level, as demonstrated by these studies, stands in contrast to most studies in the health spending variation literature, which focus on per beneficiary Medicare spending (i.e., The Dartmouth Atlas of Health Care, 2012; Congressional Budget Office, 2008; MedPAC, 2003; MedPAC, 2011; Zuckerman, Waidmann, Berenson, \& Hadley, 2010). These Medicare studies are typically conducted at more detailed units of analysis and employ rich personlevel claims data. More recent research has focused on variation in per enrollee spending for the privately insured, and has also used individual-level claims data to examine spending variation at substate level units of analysis (i.e., Baker, Bundorf, \& Kessler, 2010; Philipson, Seabury, Lockwood, Goldman, \& Lakdawalla, 2010).

In addition to specification, there were two other important methodological considerations 
regarding our modeling efforts. The first consideration, related to the unit of analysis, is that modeling at the state level versus the individual level results in higher levels of multicollinearity and endogeneity. For example, while the number of physicians in a state may not be related to an individual's income, one could argue that the supply in a state is likely related to the state's overall average per capita personal income, that is, one state with higher personal income per capita may attract more workers in general, including physicians, than would another state with relatively lower personal income per capita.

A second challenge is related to the timeseries-cross-sectional structure of our dataset. This structure generally favors the use of a fixed effects model, which accounts for cross-sectional units, such as states that are consistently geographically fixed over time, as opposed to random effects, which assume a randomly sampled population (Beck, 2001). This theoretical argument was further supported by a Hausman test. However, state fixed effects are correlated with many state-level variables of interest that are slow-moving, and the coefficients of these state characteristics of interest cannot be estimated efficiently via fixed effects models (Greene, 2003; Baltagi, 2005). As a result of these econometric challenges, our published model excluded fixed effects, though we recognize that unit-specific heterogeneity may not be captured without fixed effects; thus, we include discussions of our estimated fixed effects model variants in this paper.

\section{Data}

The OACT econometric analysis incorporates state-level data on health spending, demographics, economic characteristics, health status, health care supply, and insurance design (Exhibit 2). The estimates of health spending by state are the
State Health Expenditures by State of Residence, which are produced by OACT and are available for all 50 U.S. states for 1991-2009. ${ }^{2}$ The District of Columbia was excluded from the model dataset, as it was an outlier in interstate flows of health spending, health spending per capita, and multiple indicators related to health spending.

We calculated per capita personal income using total personal income by state from the Bureau of Economic Analysis (BEA) divided by U.S. Census Bureau state population estimates released in February, 2011 (Bureau of Economic Analysis, 2011a; U.S. Bureau of the Census, 2011). We then deflated both income and health expenditures using the chain-weighted Personal Consumption Expenditures (PCE) price index from the BEA (Bureau of Economic Analysis, 2011b). For the count of community hospital beds per 1,000 population, we utilized data from the American Hospital Association published in Health United States and the Kaiser Family Foundation State Health Facts (American Hospital Association, 1991, 2001-2011). We obtained state-level demographic characteristics from the U.S. Census Bureau (percent female aged 20-44, percent nonHispanic African American, and percent aged 65 or older; U.S. Bureau of the Census, 2011).

We calculated a "bad health" index by multiplying the reported proportion of the state population that smokes times the reported proportion of the state population that is obese (multiplied by 100), based on Behavioral Risk Factor Surveillance System survey data from the Centers for Disease Control and Prevention (CDC); this index ideally captures the intersection of residents that share these two unhealthy

\footnotetext{
${ }^{2}$ See Cuckler, et al. (2011) and CMS (2011) for a detailed discussion of the methods used to construct the state health expenditure estimates; see CMS (2012) for a discussion of National Health Expenditure Accounts methodology and classification.
} 
Exhibit 2. Dependent and Independent Variables Selected for Per Capita Personal Health Care Model, Descriptive Statistics, (1991-2009)

\begin{tabular}{|c|c|c|c|c|c|}
\hline Independent Variables & $\mathbf{N}$ & Mean & Std. Dev. & Min & Max \\
\hline $\begin{array}{l}\text { Personal health care spending per capita, adjusted by the PCE } \\
\text { price index to } 2009 \text { dollars }\end{array}$ & 950 & $\$ 5,240$ & $\$ 1,241$ & $\$ 2,909$ & $\$ 9,278$ \\
\hline $\begin{array}{l}\text { Personal income per capita, adjusted by the PCE price index to } \\
2009 \text { dollars }\end{array}$ & 950 & $\$ 33,948$ & $\$ 6,288$ & $\$ 20,070$ & $\$ 58,451$ \\
\hline Community hospital beds per 1,000 population & 950 & 3.2 & 1.0 & 1.7 & 7.0 \\
\hline $\begin{array}{l}\text { Percent of the population associated with women of } \\
\text { childbearing age }(20-44)\end{array}$ & 950 & 18.1 & 1.3 & 15.3 & 21.7 \\
\hline $\begin{array}{l}\text { Percent of the population associated with African Americans } \\
\text { (non-Hispanic) }\end{array}$ & 950 & 10.0 & 9.4 & 0.3 & 37.0 \\
\hline Percent of the population age 65 or older & 950 & 12.7 & 1.9 & 4.2 & 18.4 \\
\hline Bad health index (smoking rate ${ }^{\star}$ obesity rate) & 950 & 4.4 & 1.3 & 1.6 & 8.5 \\
\hline Percent of the population that is uninsured ${ }^{1}$ & 950 & 12.5 & 3.7 & 0.7 & 24.4 \\
\hline $\begin{array}{l}\text { HMO penetration (percent of the population by state with } \\
\text { coverage from a Health Maintenance Organization) }\end{array}$ & 950 & 17.7 & 12.1 & 0.0 & 54.2 \\
\hline Time Trend (linear) & 950 & 9.0 & 5.5 & 0.0 & 18.0 \\
\hline
\end{tabular}

NOTE: ${ }^{1}$ The uninsured population was adjusted for observed underreporting of Medicaid coverage in the Census Population Survey, based on research by Davern, Klerman, Ziegenfuss, Lynch, \& Greenberg (2009) and updated adjustment estimates from J. Ziegenfuss (personal communication, September 6, 2011).

SOURCE: Centers for Medicare \& Medicaid Services, Office of the Actuary; the Bureau of Economic Analysis (personal income per capita and PCE price index); the U.S. Census Bureau; the American Hospital Association (hospital beds); and the Centers for Disease Control and Prevention Behavioral Risk Factor Surveillance System survey data (obesity and smoking rates); the Current Population Survey (uninsured rate); and InterStudy data (HMO enrollment rate).

behaviors by state (Centers for Disease Control and Prevention, 2011). A 2006 study using the national health interview survey found overlap between the populations that are obese and smoke (4.7 percent of the U.S. population on average in 2002), a finding similar to the overlap indicated by the bad health index estimates (cross-state estimated average of 5.2 percent for the same year; Healton, Vallone, McCausland, Xiao, \& Green, 2006). To assess the comparability of the bad health index with an alternate health status indicator, we compared the correlation of the bad health index with the age-adjusted death rates from the CDC's National Vital Statistics Reports for 2008 and $2009 .{ }^{3}$ For both years, there was a relatively high correlation, suggesting that the bad health index is related to severe health conditions and may be used as a measure to control for health status. Given that death is a relatively rare occurrence for the under 65 population, and the bad health index captures behaviors from a broader spectrum of the population, the bad health index was included in the model specification.

To quantify access to care, we used an adjusted measure of the uninsured percent of the state population from the U.S. Census Bureau's Current Population Survey (CPS; Minnesota Population Center, 2011). ${ }^{4}$ Finally, our analysis included InterStudy data published in Health United States,

\footnotetext{
${ }^{3}$ In 2008, the rankings by state of these two metrics had a 0.85 correlation and, in 2009, the two rankings had a correlation of 0.83 .

${ }^{4}$ This uninsured population was adjusted for observed underreporting of Medicaid coverage in the CPS, based on research by Davern et al. (2009) and updated adjustment estimates from J. Ziegenfuss (personal communication, 2011).
} 
the Statistical Abstract of the United States, and the Kaiser Family Foundation State Health Facts on the percent of a state's population with Health Maintenance Organization (HMO) coverage (HealthLeaders-InterStudy, 1991, 1995-2011). ${ }^{5}$

\section{Methods}

\section{Published Model}

The OACT analysis released in December 2011 included an econometric model that reflected a specification and the use of econometric techniques consistent with the most relevant literature on geographic variation in health spending, measured at the state level. OACT specified the equations for the published model, which is a pooled Ordinary Least Squares (OLS) model, and a fixed effects model as follows:

$$
\begin{gathered}
\text { Published Pooled OLS Model: } \\
Y_{i, t}=\alpha+\beta X_{i, t}+\delta \text { Trend }_{t}+\mu_{i, t} \\
\text { Fixed Effects Model: } \\
Y_{i, t}=\alpha+\beta X_{i, t}+\delta \text { Trend }_{t}+\gamma \text { State }_{i}+v_{i, t}
\end{gathered}
$$

$Y_{i, t \mathbb{}}$ denotes the natural log of per capita total health care expenditures deflated by the PCE price index by state $i$ (excluding District of Columbia) and year $t\left(\mathrm{t}=1991\right.$ to 2009). $X_{i, t \text { t }}$ represents a vector of state-specific characteristics, including the natural log of per capita personal income deflated by the PCE price index, the count of community hospital beds per 1,000 population, the bad health index, and the percent of state residents who have the following characteristics: female, aged 20-44 years old; non-Hispanic and African American; aged 65 or older; uninsured state residents, or enrolled

${ }^{5} \mathrm{An} \mathrm{HMO}$ is defined as an entity that offers prepaid, comprehensive, health coverage for both hospital and physician services, through designated providers, using a fixed periodic payment for health care services (HealthLeaders-InterStudy, 1991, 1995-2011). in an HMO. Trend $d_{t \times \mathbb{X}}$ represents a linear time trend. State $_{i}$ represents binary indicator variables for each of the states ( $\mathrm{i}=1$ to 50 ), and $\mu_{i, t 区}$ and $\mathrm{v}_{i, t 区 \mathrm{X}}$ represent the error terms.

\section{Alternative Specifications and Sensitivity Analysis}

The published model discussed in Cuckler, et al. (2011) did not control for state-specific price differences, as no state-level price index for medical services was available for the entire time series. However, analysts at the BEA developed regional price parity measures that are available by state and represent 5-year averages of price differentials among states for a given type of expenditure (Aten, Figueroa, \& Martin, 2011). For this paper, we developed several alternative specifications from our published model, including an alternative that contained these price parities. ${ }^{6}$ We divided per capita personal health care spending by the overall regional price parity series (for all goods and services) for this latter alternative specification. Then we included a relative medical regional price parity, defined as the level of regional price parity for medical services divided by the overall regional price parity (for all goods and services), as a regressor in the equation. This series ideally captures the variation across states in the relative price differential between prices for medical services and prices for all goods and services.

Later in this paper we explore alternative measures of health status, time effects, and the potential influence of the size of a state health economy (and population) on the per capita regression analysis. To address issues arising from slow-moving independent variables and serial correlation, we also discuss dynamic modeling

\footnotetext{
${ }^{6}$ Regional price parities are available by several expenditure classes. For this specification, we utilized the parities for overall goods and services and for health sector services. To transform these parities into two series for 1991-2009, we deflated them by regional Consumer Price Indices.
} 
methods and the sensitivity of our published model to the inclusion of dynamic modeling elements. ${ }^{7}$

Finally, we examine the robustness of our published model through extensive sensitivity analysis, specific to time-series-cross-sectional data (Wilson \& Butler, 2007), incorporating panelcorrected standard errors (Beck \& Katz, 1995), year-specific models, and a "between" model, which regresses the mean of the dependent variable on the means of the independent variables. The between model addresses serial correlation's effect on the standard errors (Cameron \& Trivedi, 2005).

We estimated our models utilizing the EVIEWS and SAS 9.1 statistical software packages, and employed pooled ordinary least squares multivariate regression.

\section{Results}

\section{Published Model}

Consistent with prior research on health spending patterns over time, we found that measures of income (personal income per capita) and indicators of technology (linear time trend) seemed to explain most of the variation in health care spending (Smith, Newhouse, \& Freeland, 2009; Di Matteo, 2005; Exhibit 3). As indicated earlier, interrelationships among our independent variables were evident throughout our regression analysis. In particular, we observed that personal income per capita was intertwined with the time trend, which made our efforts to estimate a separate income coefficient challenging. In addition, although income ideally controls for the effect of differences in state resources to pay for health care (Acemoglu, Finkelstein, \& Ntowidigdo, 2009), the

${ }^{7}$ Specifically, we discuss the use of a lagged dependent variable (Beck \& Katz, 1995), differenced dependent/independent variables, and the inclusion of an autoregressive term in the specification (Cameron \& Trivedi, 2005). cross-state income effect we estimated also includes a pricing effect, since a regional price indicator was not included in the published model (L. Sheiner, personal communication, November 7, 2011). Consequently, we inferred the reasonableness of our income coefficient $(0.598)$ by comparing it with coefficients in similar studies on cross-state or subnational income elasticity (which ranged from 0.5 to 0.7 generally; Getzen, 2000; Rettenmaier \& Saving, 2010; L. Sheiner, personal communication, November 7, 2011). The inclusion of a linear time trend suggested roughly a 3-percent increase in health spending per year (implicitly associated with technological advances), which was within a range comparable to studies that estimate separate income and time trend coefficients (Rettenmaier \& Saving, 2010; Smith, Newhouse, \& Freeland, 2009).

In addition to income and technology, we estimated several other state-specific factors that were mainly associated with relatively higher health spending among states (Exhibit 3). A measure of health care capacity-community hospital beds per 1,000 population-had an estimated positive coefficient, suggesting that comparatively more health care supply was linked with comparatively higher health care spending levels among states (Rettenmaier \& Saving, 2010; Wright \& Ricketts, 2010). The percent of state residents who are female aged 20-44 also had an estimated positive coefficient, which indicates that states with higher shares of this population had relatively higher medical spending, likely related to medical care for childbearing (Cylus et. al, 2011). The percent of African American state residents, however, had an estimated negative coefficient, suggesting less health spending in states where this demographic group was more prominent, a finding that is likely related to economic and health status differences compared with other demographic groups (Mead et al., 2008). The percent of state residents aged 
65 or older had an estimated positive coefficient, indicating comparatively higher spending for states that had higher shares of elderly residents (Cylus et. al, 2011). ${ }^{8}$ Finally, reflecting higher medical costs for states with higher shares of residents in comparatively poorer health, the bad health index also had an estimated positive sign (Rettenmaier \& Saving, 2010).

On the other hand, type of insurance (such as membership in an HMO) or lack of insurance contributed to relatively lower health spending levels among states. We estimated a negative coefficient for the percent of uninsured state residents, likely connected to limited access to, and financial ability to pay for, medical care among the uninsured (Rettenmaier \& Saving, 2010). We also observed a negative coefficient for the share of state residents enrolled in an HMO, indicating comparatively lower health spending for HMO enrollees who are subject to tighter management of health care utilization than are enrollees in other types of insurance (Martin et al., 2007; Philipson, Seabury, Lockwood, Goldman, \& Lakdawalla, 2010).

\section{Alternate Model Specifications (without Fixed Effects)}

We first examined the impact of using a state-level relative medical price indicator (Exhibit 3). As we suspected, the addition of the relative medical price to the published model specification reduced the income elasticity from 0.598 to 0.429 , suggesting that the income elasticity in the published model is likely capturing pricing differences as well as income differences among states. Generally, with

\footnotetext{
${ }^{8}$ We also investigated more detailed age groupings (percent of state residents 65-74 years old and over 75 years of age). Both the 65-74 age grouping and the over 75 age grouping had positive, significant coefficients. The coefficient representing the percent of residents 75 years and older had a substantially higher magnitude than that of the coefficient representing the 65-74 year olds. However, the other coefficients in the model and the adjusted R squared were nearly identical to the specification with only the 65 and older age grouping.
}

the exception of the income coefficient, these results were similar to those of the published model.

We also examined the use of separate indicators for obesity and smoking incidence by state in an alternative specification, instead of the combined bad health index (Exhibit 3). The inclusion of separate variables for the obesity rate and the smoking rate resulted in a larger estimated magnitude in the health status impact than with the bad health index, which focuses solely on the overlap in the populations that are obese and that smoke. The rest of the model coefficients were nearly identical in magnitude and significance to those in the published model (except for the coefficient for the percent of African American residents losing some significance, which is intuitive given this series' high correlation with the obesity series). However, the high correlation we found between the combined bad health index and age-adjusted death rates suggests that the bad health index is capturing the association of health spending variation with variations in the share of state residents who face more significant health risks than only being obese or only being a smoker. Thus, the bad health index serves both to reduce multicollinearity and to provide a reasonable health status indication.

Given that the data reflect the effects of three recessions, we estimated a model that included individual year fixed effects relative to 1991 as an alternative to the time trend in the published model (Exhibit 3). The resulting coefficient magnitudes and directions for the non-period regressors in the alternative model were somewhat comparable to those in the published model. However, the period indicators did not reflect a lagged reduction in health spending related to recessionary periods, contrary to findings at the national level (Keehan, et al., 2012). In addition, in specific attempts to isolate the impacts of 
Exhibit 3. Published Model and Alternative Model Specifications

Dependent Variable: Log of personal health care spending per capita, adjusted by the PCE price index to 2009 dollars Independent Variables

\begin{tabular}{|c|c|c|c|c|c|c|c|}
\hline & & & Model with & & & Model & \\
\hline & & Model with & Alternative & Model with & Weighted & with State & Model with \\
\hline & Published & Relative & Health & Period Fixed & Pooled & Fixed & Regional \\
\hline Model Description & Model & Price $^{1}$ & Measure & Effects $^{2}$ & Model $^{3}$ & Effects $^{2}$ & Fixed Effects ${ }^{2}$ \\
\hline Intorcont & 1.047 & 0.150 & 1.121 & 1.192 & 0.370 & 4.306 & 3.786 \\
\hline intercept & $(0.255)^{\star *}$ & $(0.195)$ & $(0.268)^{\star *}$ & $(0.249)^{\star *}$ & $(0.196)^{\star}$ & $(0.415)^{\star *}$ & $(0.255)^{\star \star}$ \\
\hline Log of personal & 0.598 & 0.429 & 0.584 & 0.602 & 0.597 & 0.426 & 0.417 \\
\hline $\begin{array}{l}\text { income per capita, } \\
\text { adjusted by PCE } \\
\text { deflator to } 2009 \\
\text { dollars }\end{array}$ & $(0.025)^{\star *}$ & $(0.033)^{\star *}$ & $(0.026)^{\star *}$ & $(0.025)^{\star *}$ & $(0.021)^{\star *}$ & $(0.038)^{\star \star}$ & $(0.024)^{* *}$ \\
\hline $\begin{array}{l}\text { Community hospital } \\
\text { beds per } 1,000\end{array}$ & 0.019 & 0.027 & 0.020 & 0.021 & 0.059 & 0.034 & 0.037 \\
\hline population & $(0.004)^{* *}$ & $(0.004)^{\star *}$ & $(0.004)^{* *}$ & $(0.004)^{\star *}$ & $(0.003)^{\star \star}$ & $(0.008)$ & $(0.004)$ \\
\hline $\begin{array}{l}\text { Percent of the } \\
\text { population }\end{array}$ & 0.029 & 0.030 & 0.028 & 0.021 & 0.054 & -0.040 & -0.005 \\
\hline $\begin{array}{l}\text { associated } \\
\text { with women of } \\
\text { childbearing age } \\
(20-44)\end{array}$ & $(0.006)^{\star \star}$ & $(0.006)^{\star *}$ & $(0.006)^{\star *}$ & $(0.006)^{* *}$ & $(0.005)^{\star \star}$ & $(0.005)^{\star *}$ & $(0.006)$ \\
\hline $\begin{array}{c}\text { Percent of the } \\
\text { population }\end{array}$ & -0.001 & -0.001 & -0.001 & -0.001 & -0.001 & 0.001 & -0.002 \\
\hline $\begin{array}{l}\text { associated } \\
\text { with African } \\
\text { Americans }\end{array}$ & $(0.000)^{* *}$ & $(0.000)^{\star *}$ & $(0.000)^{\star}$ & $(0.000)$ & $(0.000)^{\star \star}$ & $(0.003)$ & $(0.000)^{\star \star}$ \\
\hline Percent of the & 0.029 & 0.031 & 0.029 & 0.027 & 0.036 & 0.016 & 0.007 \\
\hline $\begin{array}{l}\text { population age } 65 \\
\text { or older }\end{array}$ & $(0.002)^{* *}$ & $(0.002)^{* *}$ & $(0.002)^{* *}$ & $(0.002)^{\star *}$ & $(0.002)^{\star *}$ & $(0.004)^{\star *}$ & $(0.002)^{\star *}$ \\
\hline Bad health index & 0.023 & 0.030 & - & 0.026 & 0.014 & 0.008 & 0.016 \\
\hline & $(0.003)^{* *}$ & $(0.003)^{\star *}$ & & $(0.003)^{\star *}$ & $(0.003)^{\star *}$ & $(0.003)^{* *}$ & $(0.003)^{* *}$ \\
\hline $\begin{array}{l}\text { Percent of the } \\
\text { population that is }\end{array}$ & -0.001 & -0.002 & -0.001 & -0.002 & -0.002 & 0.000 & 0.002 \\
\hline uninsured & $(0.001)^{*}$ & $(0.001)^{* *}$ & $(0.001)^{\star}$ & $(0.001)^{\star *}$ & $(0.001)^{\star \star}$ & $(0.001)$ & $(0.001)^{\star *}$ \\
\hline HMO penetration & $\begin{array}{l}-0.001 \\
(0.000)^{\star *}\end{array}$ & $\begin{array}{l}-0.001 \\
(0.000)^{* *}\end{array}$ & $\begin{array}{l}-0.001 \\
(0.000)^{\star *}\end{array}$ & $\begin{array}{l}-0.001 \\
(0.000) *\end{array}$ & $\begin{array}{l}-0.001 \\
(0.000)^{\star *}\end{array}$ & $\begin{array}{l}-0.002 \\
(0.000)^{\star *}\end{array}$ & $\begin{array}{l}-0.001 \\
(0.000)^{\star *}\end{array}$ \\
\hline
\end{tabular}




\section{Exhibit 3. Continued Published Model and Alternative Model Specifications}

Dependent Variable: Log of personal health care spending per capita, adjusted by the PCE price index to 2009 dollars Independent Variables

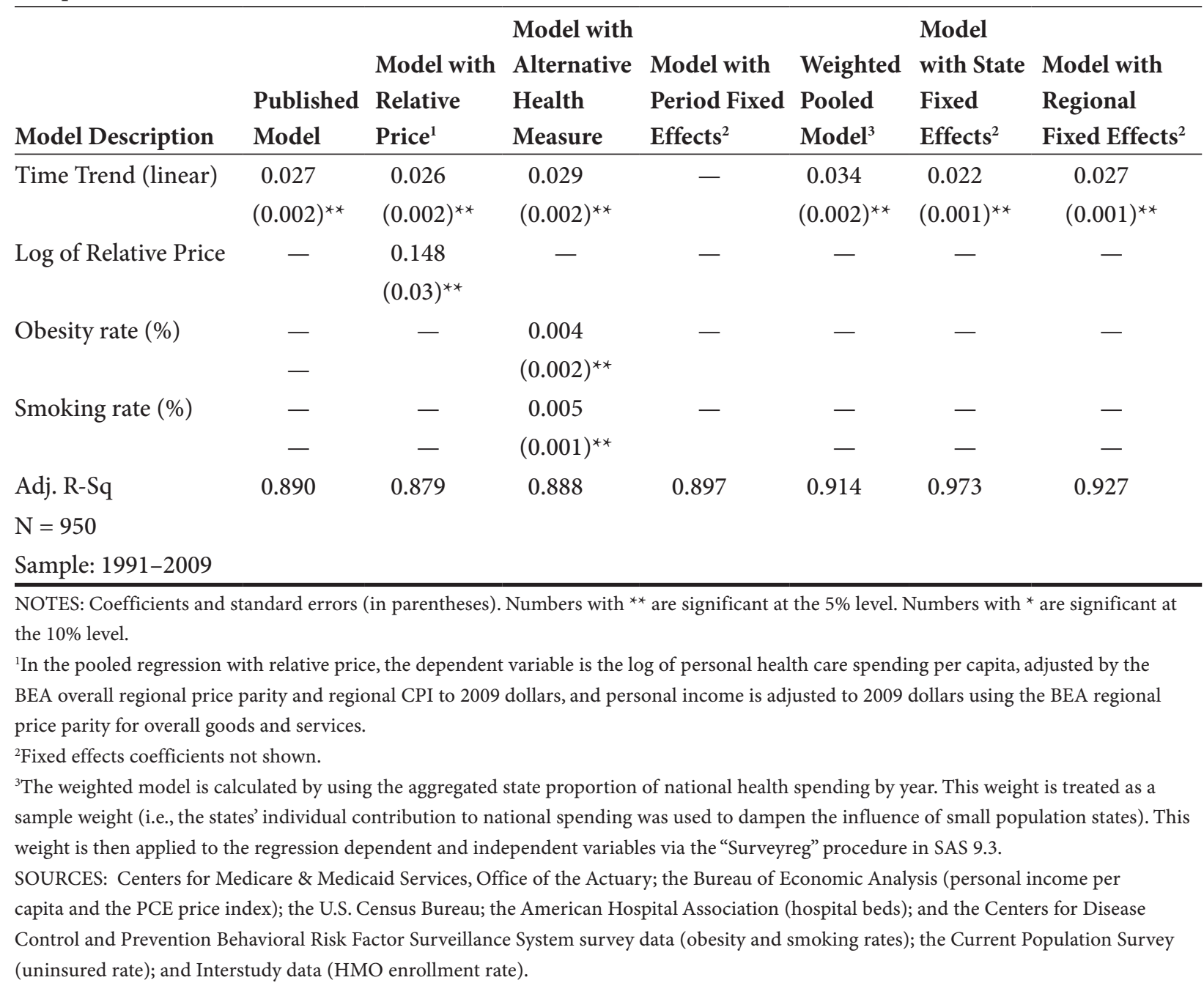

recessions in our regressions, we could not identify period-specific indicators that were consistent with findings at the national level. This result could indicate that these models are not robust enough to estimate specific time period effects. An examination of an average effect of time, that is, the trend, as is done in our published model, would likely provide more insight.

By estimating a per capita model, we are implicitly assuming that each state's data equally contributestoexplainingvariationin health spending across the country. To understand how the model is influenced by the spending patterns of states with the largest health economies and populations, and also how the model differs when it is less influenced by states with smaller health economies, we estimated a regression in which per capita personal health care by state was weighted by the aggregated state share of national spending (Exhibit 3). In significance, magnitude, and direction, the results echoed the published model regression, except that the magnitudes of the coefficients for the number 
of community hospital beds and for women 20-44 were larger in the weighted model. This result suggests that these two factors are more important in explaining the behavior of states with the highest share of health spending nationally (with some of the highest populations).

These alternative regressions generally serve to reinforce the main points illustrated by the published model and thus provide support for the variables selected in that model.

\section{Fixed Effects Models}

For our model utilizing state fixed effects, we first ran an $\mathrm{F}$ ratio test for the significance of state fixed effects versus the assumption that the constant is shared across all states; the test indicated that the fixed effects coefficients were not statistically redundant. In the fixed effects model, we saw that some independent variables from the published model specification either became insignificant or changed signs and/or magnitudes, suggesting that the estimated effects of these factors (including those representing state residents who were women of childbearing age, African American, or uninsured) were not robust to this method (Exhibit 3). In addition, the cross-state income elasticity estimated in the fixed effects model was of a smaller magnitude at 0.426 than that of 0.598 in the published model.

As noted earlier, the slow-moving nature of most of the variables in the published model specification made the estimation of the state fixed effects model challenging. Since fixed effects ideally represent local, unmeasured, unchanging characteristics, they interact with time-invariant or slow-moving state-level characteristics. An examination of the coefficients of variation (COV), for period-specific and cross-sectional specific variation, illustrated the nature of this interaction. ${ }^{9}$ This analysis makes it clear that, for every variable in the specification (except the variable representing females of childbearing age), the cross-sectional variation exceeded periodspecific variation. Accordingly, we can expect that the inclusion of fixed effects in tandem with these variables will greatly increase the multicollinearity in the model and thus make these coefficients more difficult to estimate efficiently. It is not surprising, then, that several factors lost significance in the fixed effects model.

Another concern with the coefficients estimated in the fixed effects models was the inconsistencies with OACT's prior research on spending patterns for women of childbearing age. In this research, women aged 19-64 spent an estimated 37 percent more on personal health care than males aged 19-64, a factor that increased to 73 percent when comparing women aged 19-44 with males of the same age (Cylus et. al, 2011). However, every variant of the fixed effects model we estimated resulted in a negative coefficient for women of childbearing age (including regional fixed effects),${ }^{10}$ implying the contrary result that larger proportions of women of childbearing age in a given state are associated with lower levels of spending for that state. Further analysis suggested that, across all states, the average share of this population by state fell between 1991 and 2009, largely a result of the aging baby-boomer generation (Livingston \& Cohn, 2010). Therefore, the fixed effects model coefficient may be capturing

\footnotetext{
${ }^{9}$ The coefficient of variation is defined as the standard deviation of a data series divided by the mean of that series.

${ }^{10}$ BEA-defined regions (New England, Mideast, Great Lakes, Plains, Southeast, Southwest, Rocky Mountains, and the Far West) are used here and in Cuckler, et al.(2011). We estimated a regional fixed effects model in an effort to reduce the multicollinearity associated with the state fixed effects model, and investigated the effect of this model on the coefficient for women of child bearing age. The results of the regional fixed effects model were largely similar to the model with state fixed effects with a few differences. As stated above, the coefficient for women of child bearing age was negative in both fixed effects models, but insignificant in the regional fixed effects model.
} 
this demographic shift rather than the effect of this population on health spending.

\section{Dynamic Models}

We investigated several alternative specifications with structural methods for handling issues related to time and serial correlation, including regressions with a lagged dependent variable, an autoregressive term, and a model of differences obtained by taking the difference of the dependent/independent variables with their lags. Generally, the results of these dynamic models illustrated a few key points. First, state health spending data exhibited a great deal of persistency over time; that is, the lagged dependent variable explained most of the variation in the health spending regression. In addition, by modeling dynamics directly, we obtained models of growth in the dependent variable, which negated our ability to answer why one state had a higher level of health spending than did another. Further, we observed that such modeling suggested dramatically different coefficient estimates that may be indicative of differences in growth versus level relationships. Thus, while we may not be able to extrapolate robustness of the published model (or lack of it) by comparing it to these dynamic model regressions, we learned that the persistency of the data makes it difficult to measure periodspecific variation.

\section{Robustness}

\section{Panel-Corrected Standard Errors}

In an effort to improve the efficiency of the estimates, we introduced panel-corrected standard errors for the pooled and fixed effects models to address heteroskedasticity and serial correlation. With the application of these adjustments, we treated these issues with the residuals as a nuisance and adjusted the standard errors of the regression coefficients. First, we examined the panelcorrected standard errors that are robust to crossequation (contemporaneous) correlation, as well as different error variances in each cross-section (heteroskedasticity; Exhibit 4). For the published model, the results with and without the correction for heteroskedasticity were fairly similar, except for the loss of significance from the 90-percent to the 80-percent level for the segment of the population that is African American or uninsured. In the fixed effects model, this correction resulted in no substantive difference in the significance of the coefficients.

Previously, we discussed attempts to address serial correlation with fixed effects and dynamic models. We also applied panel-corrected standard errors that are robust to arbitrary serial correlation and time-varying variances in the disturbances, which resulted in a substantial decrease in the significance of coefficients for the factors other than income, the elderly, the bad health index, and the trend (Exhibit 4). In the fixed effects model, this correction resulted in similar levels of significance with and without the corrections, except for elderly residents and the bad health index variables, which both became marginally significant at the 80-percent level. The results of these corrections suggest that income and the time trend are the most consistently robust variables to different error variance structures and modeling methods (with and without fixed effects).

\section{Examining Cross-Sectional Variation Over time}

Our next task was to examine estimates of 19 year-specific regressions to study cross-sectional variation over time (Exhibit 5). These regression coefficients were generally similar to the estimates obtained in the published model, suggesting that the published model is mostly capturing crosssectional variation. In line with this finding, we 
Exhibit 4. Published Model and Fixed Effects Model Regressions with Panel Corrected Standard Errors ${ }^{1}$

Pooled Model with State Fixed

Model Description

Published Model

Effects $^{2}$

Dependent Variable: Log of personal health care spending per capita, adjusted by the PCE price index to 2009 dollars

Independent Variables

Intercept

1.047

4.306

$(0.255)^{\star *}$

$(0.415)^{* *}$

$(0.210)^{* *}$

$(0.596)^{\star *}$

(0.822)

$(0.998)^{\star *}$

Log of personal income per capita, adjusted by the PCE deflator

0.598

0.426

to 2009 dollars

$(0.025)^{* *}$

$(0.038)^{\star *}$

$(0.018)^{\star \star}$

$(0.062)^{\star \star}$

$(0.084)^{* *}$

$(0.086)^{\star *}$

Community hospital beds per 1,000 population

$\begin{array}{lc}0.019 & 0.034 \\ (0.004)^{\star *} & (0.008)^{\star *} \\ (0.003)^{\star *} & (0.012)^{\star *} \\ (0.013) & (0.016)^{\star *}\end{array}$

Percent of the population associated with women of childbearing

0.029

$-0.040$

age (20-44)

$(0.006)^{\star *}$

$(0.005)^{\star *}$

$(0.009)^{\star *}$

$(0.006)^{\star \star}$

$(0.017)^{*}$

$(0.015)^{\star *}$

Percent of the population associated with African Americans

$\begin{array}{lc}-0.001 & 0.001 \\ (0.000)^{\star \star} & (0.003) \\ (0.001) & (0.004) \\ (0.001) & (0.01)\end{array}$

Percent of the population age 65 or older

$\begin{array}{lc}0.029 & 0.016 \\ (0.002)^{\star *} & (0.004)^{\star *} \\ (0.002)^{\star \star} & (0.006)^{\star *} \\ (0.006)^{\star \star} & (0.011)\end{array}$

Bad health index

$\begin{array}{ll}0.023 & 0.008 \\ (0.003)^{\star *} & (0.003)^{\star *} \\ (0.004)^{\star *} & (0.004)^{\star *} \\ (0.009)^{\star *} & (0.006)\end{array}$

(Continued) 
Exhibit 4. Continued Published Model and Fixed Effects Model Regressions with Panel Corrected Standard Errors ${ }^{1}$

Pooled Model with State Fixed

Model Description

Published Model Effects ${ }^{2}$

Dependent Variable: Log of personal health care spending per capita, adjusted by the PCE price index to 2009 dollars

Independent Variables

Percent of the population that is uninsured

$-0.001$

0.000

$(0.001)^{*}$

HMO penetration $-0.001$

$(0.000)^{* *}$

Time Trend (linear)

$\mathrm{N}=950$

Sample: 1991-2009

NOTES: Numbers with ${ }^{*}$ are significant at the $5 \%$ level. Numbers in with ${ }^{\star}$ are significant at the $10 \%$ level.

${ }^{1}$ Coefficients and standard errors (in parentheses). Three standard errors are presented: the first set listed are unadjusted, the second set listed are adjusted for cross-equation (contemporaneous) correlation as well as different error variances in each cross-section (heteroskedasticity), and the third set listed are adjusted for arbitrary serial correlation and time-varying variances in the disturbances. Adjusted estimates utilize panel corrected standard errors (Beck \& Katz, 1995).

${ }^{2}$ Fixed effects coefficients not shown.

SOURCES: Centers for Medicare \& Medicaid Services, Office of the Actuary; the Bureau of Economic Analysis (personal income per capita and the PCE price index); the U.S. Census Bureau; the American Hospital Association (hospital beds); and the Centers for Disease Control and Prevention Behavioral Risk Factor Surveillance System survey data (obesity and smoking rates); the Current Population Survey (uninsured rate); and InterStudy data (HMO enrollment rate).

observed that the differences between the fixed effects models and the yearly cross-sectional modeling strategies mimicked the differences between the published model and the fixed effects model. We also identified fluctuation in the significance of most of the coefficients over time, except for those of our income coefficients, which remained highly significant and were estimated within a range ( 0.5 to 0.7$)$ close to the published model estimate (0.6). Community hospital beds, women aged $20-44$, and the elderly were mostly significant in the first decade of the regressions, 


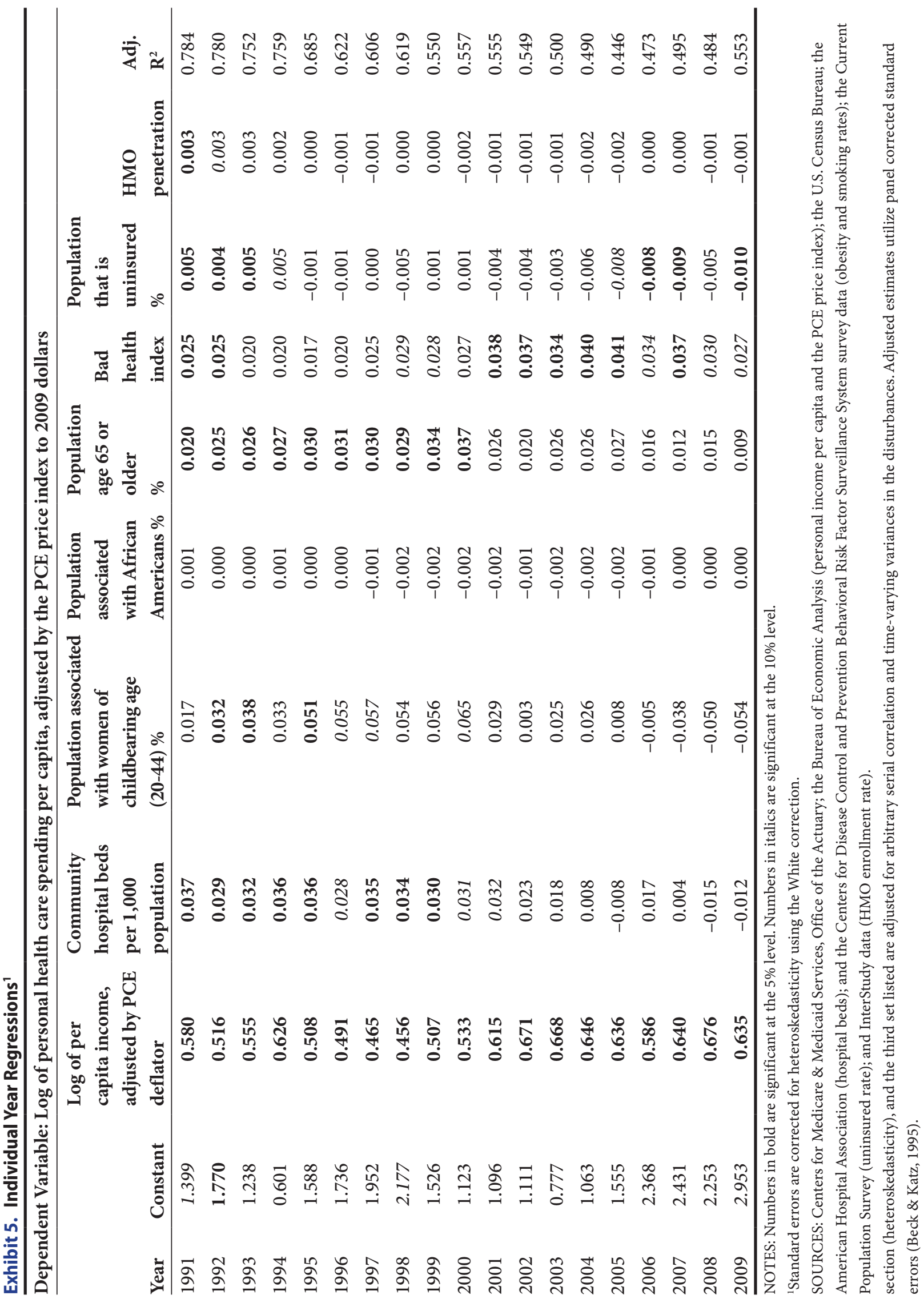

Cuckler, G. and Sisko, A. 
but generally lost significance during the second decade, while the bad health index was generally significant in the last decade. However, we found that the percent of African Americans and HMO penetration factors were not significant in the majority of these regressions. Notably, uninsured state residents were most significant in the early 1990s and in the most recent years of the data, suggesting that this variable is likely capturing cyclical trends in the economy. Finally, we observed lower adjusted R-squared estimates in the yearly regressions compared to the full panel data set regressions, which suggests some bias in the adjusted R-squared in the pooled models related to serial correlation.

\section{Estimating a Model of Means: the "Between" Model}

Because nearly all of our variables of interest are slow-moving, we estimated a "between" model using the means of the variables over time (Exhibit 6). The between model is conceptually similar to the published model, but attempts to remove the element of time from the regression and thus theoretically addresses serial correlation. This technique dampens periodic effects, such as economic cycles. While the results of this regression were somewhat close to the published model, they differ in that some factors become only marginally significant. However, the similarity in the magnitude and significance of several of the key factors in the between model supports the published model specification.

\section{Discussion}

This examination of alternative specifications and sensitivity analysis provides us with several insights. First, though the published model is most consistent with prior research, the regressions are fairly sensitive to methods; consequently, we should use a compilation of models to inform our interpretation of the significance and magnitude of regression coefficients. Second, though the data are generally sluggish in that their cross-sectional variation largely exceeds their period-specific variation, there are nontrivial changes over the last two decades that are important to consider when reviewing regression results. However, the nature of these sluggish variables results in inefficient estimates arising from serial correlation. Third, there are tradeoffs involved in treating omitted variable bias, multicollinearity, serial correlation, and heteroskedasticity. Accordingly, we did not identify a sole model that effectively treats all these issues collectively. The non-dynamic models mostly capture cross-sectional variation, which indicates that they estimate a mean effect of differences in state characteristics on health spending between states averaged over time.

Ultimately, this sensitivity analysis is meant to enhance our discussion of factors that influence variation in health spending among states, and their robustness to different modeling strategies. We found that per capita income, community hospital beds, the share of the elderly population, and the time trend are consistently important factors in explaining level variation in state health spending per capita among states. The inclusion of a price measure does indeed reduce the income coefficient, suggesting that the cross-state income elasticity is likely in the $0.4-0.5$ range. We also found that the bad health index by stateis somewhat consistent across methods and ranged from being marginally to highly significant over time. With the aging of the baby-boomer generation and their entrance into the Medicare program over the next decade, the elderly share of state residents will likely become more significant in future regression analyses on state health expenditures. In addition, rising obesity rates (projected to increase to more than 44 percent of the population by 2030) will likely have significant health cost 
Exhibit 6. Between Model Regression Results ${ }^{1,2}$

Dependent Variable: Log of personal health care spending per capita, adjusted by the PCE price index to 2009 dollars

Independent Variables

Parameter

Intercept

0.814

Personal income per capita, adjusted by the PCE deflator to 2009 dollars

Community hospital beds per 1,000 population

Percent of the population associated with women of childbearing age (20-44)

Percent of the population associated with African Americans

Percent of the population age 65 or older

Bad health index

Percent of the population that is uninsured

HMO penetration

Adj. $\mathrm{R}^{2}$

$\mathrm{N}=50$

Sample: Average over 1991-2009

NOTES: Numbers with ${ }^{*}$ are significant at the $5 \%$ level. Numbers in with ${ }^{\star}$ are significant at the $10 \%$ level.

${ }^{1}$ All variables (dependent and independent) are calculated as the mean of the cross-sectional value over the full regression time period (1991-2009).

${ }^{2}$ Standard errors are corrected for heteroskedasticity using the White correction.

SOURCES: Centers for Medicare \& Medicaid Services, Office of the Actuary; the Bureau of Economic Analysis (personal income per capita and the PCE price index); the U.S. Census Bureau; the American Hospital Association (hospital beds); and the Centers for Disease Control and Prevention Behavioral Risk Factor Surveillance System survey data (obesity and smoking rates); the Current Population Survey (uninsured rate); and InterStudy data (HMO enrollment rate).

consequences in future regression analyses (Levi, Segal, St. Laurent, Lang, \& Rayburn, 2012). Thus, it will be necessary to monitor the effect of these underlying state factors in future modeling efforts if we are to understand state health cost trends, in the face of significant changes to the health care system under the Affordable Care Act, particularly related to the scheduled coverage expansions in 2014. Though the rate of uninsured residents by state is not consistently significant across methods, it is useful in understanding period-specific effects, such as economic cycles, on variation over time. On the other hand, gender and race were not robust to multiple modeling methodologies, which suggests that these two factors are not as important in explaining health spending variation when examined at the statelevel unit of analysis. 


\section{Limitations and Future Research}

As discussed in Cuckler, et al. (2011) and shown in our sensitivity analysis, our published model has limitations. For example, the model cannot be used to make claims about causality and/or the direction of causality. In addition, the relatively small sample size and limited availability of effective instruments impede effective estimates of multistage structural models to address endogeneity. Both concerns will require additional research and years of data. The analysis also shows that results are sensitive to the methods selected; therefore, the results must be interpreted with caution.

The results presented here also suggest areas where we could expand the research questions that could be covered by our modeling approach. A natural next step would be to further develop models of variation in per capita total personal health care spending growth over time, using dynamic modeling techniques. Similarly, further work with state price differentials for health services developed by the BEA would allow us to improve upon our currently published model by better controlling for state-by-state price differences.

\section{Conclusions}

The sensitivity analysis and evaluation of alternative specifications demonstrated in this paper provide evidence in support of OACT's published model results presented in Cuckler, et al. (2011). Given the sensitivity of our regression results to methodological choice, however, we found that multiple modeling strategies should be utilized to verify the reasonableness of regression coefficient estimates. Generally, we observed that a few state-specific factors (income, the number of hospital beds, and the share of elderly residents) and technology (as measured by a linear time trend) explained most of the variation in health spending between states. However, the sluggish nature of many state-specific variables dampened the efficiency of these estimates via serial correlation. Despite this sluggishness, we identified nontrivial changes in factors explaining health spending over the last two decades, which would not be captured in an analysis of a single-year crosssectional regression, particularly given the significant impact of the recent recession.

\section{Correspondence}

Gigi Cuckler, M.A., M.B.A., National Health Statistics Group in the Office of the Actuary, Centers for Medicare \& Medicaid Services, at DNHS@cms.hhs.gov

\section{Acknowledgment}

The authors would like to acknowledge the contributions of Stephen Heffler, Mark Freeland, Sheila Smith, Aaron Catlin, and Cathy Curtis for their helpful comments throughout the preparation of this manuscript.

\section{References}

Acemoglu, D., Finkelstein, A., \& Ntowidigdo, M. (2009). Income and Health Spending: Evidence from Oil Price Shocks (NBER Working Paper No. 14744). Cambridge, MA: National Bureau of Economic Research.

American Hospital Association (1991, 2001-2011). Community hospital beds per 1,000 resident population, by State: Chicago. Retrieved from http://www.aha.org/

Aten, B., Figueroa, E., \& Martin, T. (2011, May). Research Spotlight: Regional Price Parities by Expenditure Class, 2005-2009. Survey of Current Business, 91(5), 73-87.

Baker, L. C., Bundorf, M. K., \& Kessler, D. P. (2010). HMO Coverage Reduces Variations in the Use of Health Care Among Patients 
Under Age Sixty-Five. Health Affairs, 29(11), 2068-2074. PubMed http://dx.doi.org/10.1377/ hlthaff.2009.0810

Baltagi, B. H. (2005). Econometric Analysis of Panel Data (3rd ed.). Chichester, West Sussex, England: John Wiley \& Sons.

Beck, N. (2001). Time-Series-Cross-Section Data: What Have We Learned in the Past Few Years? Annual Review of Political Science, 4, 271-293. http://dx.doi.org/10.1146/annurev. polisci.4.1.271

Beck, N. \& Katz, J. N. (1995). What to do (and not to do) with Time-Series Cross-Section Data. The American Political Science Review, 89(03), 634-647. http://dx.doi.org/10.2307/2082979

Bureau of Economic Analysis (2011a). Table SA04. State income and employment summary. Retrieved August 8, 2011, from http://www.bea. gov/iTable/iTable.cfm?reqid $=70 \&$ step $=1$ \&isuri $=1 \& \operatorname{acrdn}=4$

Bureau of Economic Analysis (2011b). Table 1.1.9. Implicit Price Deflators for Gross Domestic Product [Data file]. Retrieved September 12, 2011, from http://www.bea.gov/iTable/iTable. $\mathrm{cfm}$ ? ReqID=9\&step=1\# reqid=9\&step=3\&isur $\mathrm{i}=1 \& 903=13$

Cameron, A. C., \& Trivedi, P. K. (2005). Microeconometrics: Methods \& Applications. New York: Cambridge University Press.

Centers for Disease Control and Prevention (2011). Behavioral Risk Factor Surveillance System [Data File]. Retrieved from http://www. cdc.gov/brfss/

Centers for Medicare \& Medicaid Services (2011). State Health Expenditure Accounts, 1991-2009: Converting Estimates from State of Provider to State of Residence. Retrieved from
http://www.cms.gov/Research-Statistics-Dataand-Systems/Statistics-Trends-and-Reports/ NationalHealthExpendData/Downloads/resmethodology.pdf

Centers for Medicare \& Medicaid Services (2012). National Health Expenditure Accounts: Methodology Paper, 2010. Retrieved from http://www.cms.gov/Research-Statistics-Dataand-Systems/Statistics-Trends-and-Reports/ NationalHealthExpendData/Downloads/dsm10.pdf

Congressional Budget Office (2008). Geographic Variation in Health Care Spending. (Publication No. 2978). Retrieved from http://www.cbo.gov/ publication/41669

Cuckler, G., Martin, A., Whittle, L., Heffler, S., Sisko, A., Lassman, D., \& Benson, J. (2011, December). Health Spending by State of Residence, 1991-2009. Medicare \& Medicaid Research Review, 1(4), E1-E31. PubMed http:// dx.doi.org/10.5600/mmrr.001.04.a03

Cylus, J., Hartman, M., Washington, B., Andrews, K., \& Catlin, A. (2011). Pronounced Gender And Age Differences Are Evident In Personal Health Care Spending Per Person. Health Affairs, 30(1), 153-160. PubMed http://dx.doi.org/10.1377/ hlthaff.2010.0216

Davern, M., Klerman, J. A., Ziegenfuss, J., Lynch, V., \& Greenberg, G. (2009). A partially corrected estimate of Medicaid enrollment, uninsurance: Results from an imputational model developed off linked survey, administrative data. Journal of Economic and Social Measurement, 34(4), 219-240.

Di Matteo, L. (2005). The macro determinants of health expenditure in the United States and Canada: assessing the impact of income, age distiribution and time. Health Policy 
(Amsterdam), 71, 23-42. http://dx.doi. org/10.1016/j.healthpol.2004.05.007

Getzen, T. E. (2000). Health Care is an Individual Necessity and a National Luxury: Applying Multilevel Decision Models to the Analysis of Health Care Expenditures. Journal of Health Economics, 19, 259-270. PubMed http://dx.doi. org/10.1016/S0167-6296(99)00032-6

Greene, W. H. (2003). Econometric Analysis, 5th Edition [Data file]. Upper Saddle River, NJ: Prentice Hall.

HealthLeaders-InterStudy(1991,1995-2011).Persons Enrolled in Health Maintenance Organizations (HMO's) by State: Nashville. Retrieved from http:// www.healthleaders-interstudy.com/

Healton, C. G., Vallone, D., McCausland, K. L., Xiao, H., \& Green, M. (2006). Smoking, obesity, and their co-occurrence in the United States: cross sectional analysis. BMJ (Clinical Research Ed.), 333, 25-26. PubMed http://dx.doi.org/10.1136/ bmj.38840.608704.80

Keehan, S. P., Cuckler, G. A., Sisko, A. M., Madison, A. J., Smith, S. D., Lizonitz, J. M., . . Wolfe, C. J. (2012).National Health ExpenditureProjections: Modest Annual Growth Until Coverage Expands And Economic Growth Accelerates. Health Affairs, 31(7), 1600-1612. PubMed http://dx.doi. org/10.1377/hlthaff.2012.0404

Levi, J., Segal, L. M., St. Laurent, R., Lang, A., \& Rayburn, J. (2012). F as in Fat: How Obesity Threatens America's Future. Washington D.C.: Trust for America's Health Retrieved from the Robert Wood Johnson Foundation at http://www.rwjf.org/content/dam/farm/reports/ reports/2012/rwjf401318

Livingston, G., \& Cohn, D. (2010). The New Demography of American Motherhood. Pew
Research Center Social \& Demographic Trends Report. Retrieved from http://pewsocialtrends. org/files/2010/10/754-new-demography-ofmotherhood.pdf

Martin, A. B., Whittle, L., Heffler, S., Barron, M. C., Sisko, A., \& Washington, B. (2007). Health Spending By State Of Residence, 1991-2004. Health Affairs, 26(6), w651-w663. PubMed http://dx.doi.org/10.1377/hlthaff.26.6.w651

Mead, H., Cartwright-Smith, L., Jones, K., Ramos, C., Woods, K., \& Siegel, B. (2008, March). Racial and Ethnic Disparities in U.S. Health Care: A Chartbook (The Commonwealth Fund Publication No. 1111).

MedPAC (2003). Report to the Congress: Variation and Innovation in Medicare (Chapter 1, pp. 3-15). Retrieved from http://www.medpac.gov/ documents/June03_Entire_Report.pdf

MedPAC (2011). Report to the Congress: Regional Variation in Medicare Service Use. Retrieved from http://www.medpac.gov/documents/Jan11_ RegionalVariation_report.pdf

Minnesota Population Center (2011). Integrated Public Use Microdata Series (IPUMS) [Data file]. Retrieved from http://cps.ipums.org/cps/

Philipson, T. J., Seabury, S. A., Lockwood, L. M., Goldman, D. P., \& Lakdawalla, D. N. (2010). Geographic Variation in Health Care: The Role of Private Markets. Brookings Papers on Economic Activity, 325-355. http://dx.doi.org/10.1353/ eca.2010.0006

Rettenmaier, A. J., \& Saving, T. R. (2010). Perspectives on the Geographic Variation in Health Care Spending. Retrieved from http://www.aei.org/ files/2010/05/18/Rettenmaier\%20and\%20 Saving \% 20-\%20 Perspectives $\% 20$ on $\% 20$ Geographic\%20Variation\%20in\%20Health\%20 Spending.pdf 
Rettenmaier, A. J. \& Wang, Z. (2012). Regional Variations in Medical Spending and Utilization: A Longitudinal Analysis of US Medicare Population. Health Economics, 21(2), 67-82. PubMed http://dx.doi.org/10.1002/hec.1700

Smith, S., Newhouse, J., \& Freeland, M. (2009). Income, Insurance, And Technology: Why does Health Spending Outpace Economic Growth? Health Affairs, 28(5), 1276-1284. PubMed http://dx.doi.org/10.1377/hlthaff.28.5.1276

The Dartmouth Atlas of Health Care (2012). Research Articles. Retrieved from http://www. dartmouthatlas.org/publications/articles.aspx

U.S. Bureau of the Census (2011). Annual Estimates of the Population for the United States and States. Retrieved, June 1, 2011, from http:// www.census.gov/popest/index.html
Wilson, S. \& Butler, D. (2007). A Lot More to Do: The Sensitivty of Time-Series-Cross-Section Analysis to Simple Alternative Specifications. Political Analysis, 15(2), 101-123. http://dx.doi. org/10.1093/pan/mpl012

Wright, D. B. \& Ricketts, T. C. (2010). The Road to Efficiency? Reexamining the Impact of the Primary Care Workforce on Health Care Utilization Rates. Social Science \& Medicine, 70, 2006-2010. PubMedhttp://dx.doi.org/10.1016/j. socscimed.2010.02.043

Zuckerman, S., Waidmann, T., Berenson, R., \& Hadley, J. (2010). Clarifying Sources of Geographic Differences in Medicare Spending. The New England Journal of Medicine, 363(1), 5462. http://dx.doi.org/10.1056/NEJMsa0909253 PubMed 